\title{
A REVIEW OF LIGHTNING-RELATED OPERATING EVENTS AT NUCLEAR POWER PLANTS
}

\author{
Chris Rourk \\ Member IEEE \\ U.S. Nuclear Regulatory Commission \\ Washington, D.C.
}

\begin{abstract}
Lightning-related events at nuclear power plants for the period 1980 to 1991 were reviewed to identify events involving equipment misoperation and damage. Based upon this review, the following observations were made: (1) lightning strikes to transmission lines do not appear likely to result in a total loss of offsite power at nuclear power plants, (2) high frequency electrical transients caused by these line strikes do not appear to cause significant equipment damage or misoperation, (3) low voltage conditions caused by the subsequent ground faults of a transmission line after a lightning strike can cause protective relaying to operate, which may result in spurious actuation of equipment, and (4) protection of the plant structures from local strikes appears to be adequate. Local strike effects, such as ground potential rise of the station grounding grid, appear to be the cause for equipment damage when it has occurred.
\end{abstract}

Keywords: Lightning Strike, Lightning Surge, Nuclear Power Plant, Loss of Offsite Power, Station Blackout, Transmission Line Transient, Ground Potential Rise.

\section{Introduction}

Power plants are protected from lightning by several design features. These features include transmission line shield wires, structural grounding and lightning rods, surge arresters, and station grounding practices. Although these protective features mitigate the effects of lightning, they do not prevent the occurrence of local strikes, nor do they prevent the loss of offsite power to the plant. To receive an operating license, an applicant for a nuclear power plant license must demonstrate that the plant can safely shut down after a loss of all

94 WM 108-1 EC A paper recommended and approved by the IEEE Nuclear Power Engineering Committee of the Power Engineering Society for presentation at the IEEE/PES 1994 winter Meeting, New York, New York, January 30 - February 3, 1994. Manuscript submitted December 17, 1992; made available for printing November 29, 1993. offsite power. These measures are considered sufficient to adequately protect nuclear power plants from lightning.

Licensees are required under Title 10 of the Code of Federal Regulations in 10 CFR Part 50, "Domestic Licensing of Production and Utilization Facilities," (10 CFR 50.36, 50.72, and 50.73), to report operational events that involve potential or actual degradation of safety systems. These reports are called licensee event reports (LERs), and they are reviewed by the NRC staff to determine if the plant systems responded as required. These reviews have not revealed any significant safety concerns associated with lightning.

In addition, these LERs are reviewed annually to determine if they represent significant precursors to potential severe core damage accidents. These precursor events are analyzed in greater depth, to estimate the conditional probability of core damage resulting from the event. This estimate is expressed as a change in core damage frequency (CDF). The analysis is performed using probabilistic risk assessment (PRA) modeling, and it is reported in NUREG/CR-4674, which is updated regularly [1]. These additional reviews have not revealed any significant safety concerns resulting from the affects of lightning on nuclear power plants.

A review of LERs reporting lightning-related events for the period 1980-1991 was conducted recently to determine whether any trends were developing that indicate potential problems, and the results of this review are presented here. This review did not indicate the need for additional regulation of lightning protection at licensed plants, but it was noted that some of the findings may be of general interest to designers and operators of nuclear and fossil power generation facilities.

\section{Loss of Offsite Power}

A loss of offsite power occurs when any transmission line connecting the plant to the power system is disconnected by circuit breakers. If every transmission line connecting the plant to the power system is disconnected, a total loss of offsite power occurs. Plants are required to have on-site backup power sources, such as diesel generators, to provide sufficient power to safely shut down the plant in the event of a total loss of offsite power. The plant is also required to have sufficient battery power in an uninterruptible power supply to start the diesel generators. If the diesel generators fail to 
start, a complete loss of power to the essential and nonessential switchgear buses could occur. This scenario is referred to as station blackout.

Of the 174 events reported, 6 events, or $3.4 \%$, involved the loss of all offsite power sources. Two of these events occurred at $0 \%$ power. In addition, 33 events or $19 \%$ involved the loss of one offsite power source from transmission line trip, 7 of which occurred at $0 \%$ power. Three events, or $1.7 \%$, involved the loss of two offsite power sources, which did not constitute a total loss of offsite power.

Based upon these events that span a period of approximately 967 years of reactor operations, the frequency of a total loss of offsite power from lightning is approximately 0.0062 events per reactor year. One of the assumptions made in the study of station blackout at nuclear power plants by the NRC [2] is that the frequency of a loss of all offsite power from all causes is 0.1 events per reactor year, and the contribution to this frequency by lightning was small. It is concluded that the results of this study based upon operating experience do not conflict with the assumptions made for station blackout.

\section{No Reactor Trip Reported}

Of the 174 events examined, 116 events or $67 \%$ involved no reactor trip. In addition, 56 events or $32 \%$ occurred with the reactor at $0 \%$ power, which roughly corresponds to the average capacity factor for U.S. nuclear power plants of $69 \%$ for 1991 [3]. From this observation it can be inferred that nuclear power plants are not more sensitive to lightning effects while generating power. It is noted, though, that most of the events which occurred at $0 \%$ power involved the starting of diesel generators or actuation of systems required to safely shut down the reactor because of low system voltage, and did not result in the types of equipment damage associated with local strikes in Section 8 of this paper.

4. Damage to Fire Protection Equipment and Events Involving Fires

A lightning strike could simultaneously disable fire protection equipment and possibly cause a fire. Several notable events have occurred that involved the loss of fire protection capability. One licensee experienced two inadvertent actuations of a halon system and responded by disarming the system on 24 different occasions prior to resolving the problem. The plant was in cold shutdown at the time with the reactor defueled. Another licensee reported that the fire protection computer was offline for over seven days from an electrical transient caused by lightning. It was not clear from these LERs whether the fire protection equipment was affected by local lightning effects or power line transients. A total of 6 events occurred which involved the unintentional loss of fire protection from lightning.

In addition to these events, there were four events reported that involved a fire at the plant caused by lightning. Two of these events involved the burning of lightning arresters on station service transformers, one involved the explosion of an oil circuit breaker, and one involved arcing in the $6.9 \mathrm{kV}$ switchgear compartment. It is likely that additional fires have occurred that were not reported on LERs, because to be reportable, an event must involve actuation or unavailability of safety-related equipment or systems.

Although it is possible that a lightning strike may result in a fire simultaneously with the loss of fire protection, such an event has not occurred in approximately 967 years of plant operations. A frequency of 0.001 events per reactor year for this scenario is therefore defensible. Subsequently, the core damage frequency resulting from a lightning-induced fire with concurrent loss of fire protection is estimated to be less than $1.0^{*} 10^{-7}$ events per reactor year, due to mitigating factors such as fire walls and barriers, alternate means of fire detection and suppression, and redundant core cooling systems. In addition, it is not clear whether the likelihood of this postulated event would be decreased by additional lightning protection, as none of the reported events identified failure of lightning protection as a contributing factor.

\section{High-Frequency Voltage Transients and Low Voltage Effects}

Lightning can affect a power plant by one of several mechanisms. If lightning strikes a transmission line, transmission tower, or shield wire, a surge wave will be created on the transmission line with a current magnitude that is determined by the charge characteristics of the lightning and the location of the strike. If lightning strikes locally, the effect on the plant will depend on the magnitude and distribution of ground potential rise and the capacitive and inductive coupling of plant systems and components to the lightning channel. Therefore, it is critical to know or determine the location of the strike.

The information in some LERs suggests that an event is caused by a high-frequency voltage transient from the transmission line entering the plant through either the main unit transformer or one of the station service transformers. Nevertheless, most events that resulted in component damage appear to have been caused by a local strike. For example, 42 events involved the loss of one or more offsite power sources, but only one of these events involved any equipment damage. The loss of an offsite source of power from lightning usually entails the line being struck by lightning, the line shorting to ground at some point, and a ground fault then tripping line protection (lightning may also cause a transmission line fault if it strikes a tower). These events create many high-frequency surge waves on the transmission line and should correlate to 
equipment misoperation or damage if these surges propagate into the plant instrumentation and controls equipment. This effect did not occur in $41(97 \%)$ of the events that involved the loss of transmission lines.

These 41 events did include some adverse equipment effects that appeared to result from low voltage at the plant, such as tripping of equipment protective relays on undervoltage, but they did not involve any equipment damage or failure. This observation is supported by one licensee who reported six events that entailed the loss of a transmission line from a lightning strike and four other events in which the same transmission line was lost from causes other than lightning. These ten combined events caused various combinations of reactor protection system (RPS) actuation, reactor building HVAC systems tripping, standby gas treatment system initiation, reactor recirculation pump scoop tube lockup, radiation monitor tripping, and chillers tripping. These LERs do not attribute the actuation and alarms to a voltage spike or surge, but attribute them to low voltage. Appendix I to this paper lists and describes the LER numbers.

The single event involving a loss of all offsite power that did result in equipment damage was complicated by several factors. This event began with the destruction of a lightning arrester on a station service transformer and flashover of a second transmission line at a disconnect switch, which resulted in the loss of all offsite power. In addition, the nonessential uninterruptible power supply failed to transfer to its back-up source, and miscellaneous power supplies, amplifiers, and recorders required unspecified repairs. The public phone system is believed to have been damaged by a separate lightning event, as was other offsite telecommunications equipment by a third event, resulting in a loss of all offsite communications. The occurrence of multiple, isolated, lightning-related failures indicates that this event may have been caused by a combination of local and power line effects. Nevertheless, all safety-related reactor systems functioned as required.

If high-frequency voltage transients from lightning strikes to the transmission system were responsible for equipment damage, these 41 LERs that involve such events should provide the most compelling evidence. All other LERs that involve equipment misoperation or damage from lightning either state that the events were caused by local strikes or it can be otherwise established that the damage was caused by a local strike. It is not stated in any of these other LERs that the event was caused by a lightning strike to the transmission line, or that transmission line protective relaying actuated or indicated. In addition, several of these other events involve motor-generator-fed sources, which should be immune to highfrequency voltage transients from the transmission system. Based upon these observations, it is concluded that highfrequency power line transients are not a primary source of nuclear power plant equipment damage by lightning.

\section{Control Rod Drive Power Supply Overvoltage Protection Actuation}

Twenty events have occurred that involve actuation of the control rod drive dc power supply overvoltage protection. When this occurs, the control rod gripper units are de-energized, which causes the control rods to fall into the reactor core. The reactor then trips on high negative flux rate. Although an unnecessary reactor trip by itself is not a safety concern, it is undesirable because of equipment wear and other equipment cycling stress. Under the circumstances, a reactor trip is the preferred plant response and the frequency (20 events in 967 reactor operating years) is low enough that the adverse effects are expected to be minimal. These events appear to be caused by local strikes and have not been accompanied by the loss of one or more offsite power sources. Some of these LERs state that the lightning struck the containment and was conducted through the containment penetrations, which induced a transient signal in the cables passing through these penetrations. However, no estimate has been made of the inductive or capacitive coupling between the penetrations and the cables passing through them, and no estimate has been made of the current or voltage induced in the cables. In addition, most of these plants reported that the containment structural lightning protection was in good condition, which would indicate that the lightning charge was conducted to ground through the containment ground conductors. It would appear that ground potential rise (GPR) is a likely explanation for these events $[4,5]$. The two events described here involved positive identification of the correlation between a local strike and control rod drive power supply overvoltage protection actuation.

LER No. 457-89-4, Attributed to lightning striking containment building (recorded on videotape)

Because of repeated occurrences of control rod drive power supply overvoltage trips during electrical storms, the lightning was videotaped. Four strikes occurred to plant structures over a seven-minute period. Two strikes hit the auxiliary building, one strike hit the station switchyard, and the last strike hit the containment building. Within seconds of the last strike, the reactor tripped from high negative flux rate of change, which was caused by actuation of the control rod drive power supply overvoltage protection circuits. Numerous spurious alarms were noted. No physical damage occurred. 

striking containment.

Eyewitnesses reported that lightning struck the low voltage switchyard, the containment building, and various other power block buildings. No fire or lightning damage was noted. The reactor tripped from high negative flux rate of change, which was due to actuation of the control rod drive power supply overvoltage protection circuits. In addition, the emergency response facility computer became inoperable, the security and fire protection computers alarmed, a Supervisory Logic III card was damaged, and a 100-volt dc power supply in the logic cabinet was found to be defective.

LER numbers for other events involving control rod drive power supply overvoltage protection actuation are provided in Appendix I.

\section{Meteorological Equipment Damage}

Of the 174 events examined, 18 or $10.3 \%$ involved damage to meteorological equipment mounted on towers Such events do not threaten the ability of the plant to safely shut down. These events establish that one indication of a local lightning strike is failure of equipment on a meteorological tower.

\section{Other Equipment Damage}

Most events involving damage to equipment, such as level transmitters, blown fuses, or resistance temperature detectors (RTDs), appear to be due to local strikes. Two events that involved equipment damage are described below.

\subsection{LER 304-86-16, attributed to lightning striking con-} tainment.

Five RTDs, one level transmitter, and three low-level amplifiers failed simultaneously with the actuation of 8 out of 10 control rod drive overvoltage protection circuits. These events were attributed to lightning striking containment, but the LER does not state whether the strike was observed. In addition, many annunciators spuriously alarmed, including all annunciators associated with the $345 \mathrm{kV}$ switchyard. These events occurred on Unit Two, which was tripped by the loss of the five RTDs. Unit One was operating at the time and did not experience a trip.

8.2 LER 413-89-21, attributed to a lightning strike at or near the refueling water storage tank

Two out of four level transmitters failed on the refueling water storage tank during a thunderstorm. One level transmitter had failed during a previous thunderstorm. The grounding on the tank was embedded in concrete and could not be verified, and additional grounding was installed as a result of this event. The LER does not state that any other equipment damage or misoperation occurred.

These and similar events suggest that local effects are responsible for equipment damage. When equipment damage occurs, it usually involves more than one piece of equipment and may be accompanied by false actuation of alarms, indicators, and systems. Some LERs attribute these events to inductive or capacitive coupling of cables passing through containment penetrations to lightning currents flowing through the penetrations. If structural protection is installed on the containment building, such as lightning rods and ground conductors, lightning currents should not be conducted through the containment penetration.

An alternative explanation for these events may be ground potential rise, based upon the results of a simulation of lightning striking a power station [5]. The electromagnetic transient modeling program EMTP was used to model the structure and grounding grid of a power station, and a surge was injected into the model at a point that represented the containment building structural lightning protection. It was reported that the ground potential rise accompanying the strike could create voltage transients on station cabling through inductive and capacitive coupling to station structures, cable trays, and conduit. This scenario seems more plausible than coupling between lightning currents and cables at containment penetrations. At this point, it is unclear whether ground potential rise has any regulatory significance.

\section{Lightning Dissipation Arrays}

One licensee installed lightning dissipation arrays in order to minimize the effects of lightning. It is noted that there has been no evidence that lightning dissipation arrays can protect a structure by dissipating electric charge prior to the creation of the lightning. Some experts have dismissed claims of the efficacy of lightning dissipation arrays [6], and the experiences of this licensee lend support to this point of view.

This licensee reported six local strike events between August 1988 and July 1992, and all six involved automatic reactor scrams caused by spurious average power range monitor indications. After the first two events, in August 1988 and in July 1989, the licensee proposed installing lightning dissipation arrays. A third event occurred in November 1989, before the arrays were installed. The fourth event occurred in August 1991. The LER for this event states that "[t]he lightning strike...was able to penetrate the protection array of [the] lightning dissipation system." The fifth event occurred in 
November 1991, and the sixth event occurred in June 1992. After this sixth event, the licensee reported taking seven separate actions for preventing future events, such as installation of magnetic shielding and improved equipment chassis grounding. As indicated by the events described in Section 6 of this paper, there is apparently a strong correlation between the systems affected by a local strike and the location of the strike. Therefore, it is concluded from the 6 events experienced by this licensee that, although lightning dissipation arrays may protect plant structures from lightning, they do not prevent local lightning strikes and the associated effects of ground potential rise by dissipating electric charge before it causes lightning.

10. Conclusion

A review of lightning-related events at nuclear power plants from 1980 to 1991 indicates that the most significant impact on plant operations that may be caused by lightning is from the effects of local strikes, such as ground potential rise. This conclusion is based on a large number of events which involved the loss of one or more transmission lines to the plant which did not also result in equipment damage, or misoperation for reasons other than low voltage. Based upon these events, it appears that high-frequency voltage transients created on the transmission system by lightning do not cause significant equipment misoperation or damage. In addition, equipment damage or misoperation resulting from local strikes does not appear to create a significant risk to plant safety.

\section{ACKNOWLEDGEMENT}

The author would like to thank Prasad Kadambi for his helpful advice.

\section{REFERENCES}

1) United States Nuclear Regulatory Commission, "Precursors to Potential Severe Core Damage Accidents," NUREG/CR-4674, Volumes 1 through 18.

2) United States Nuclear Regulatory Commission, "Station Blackout," NUREG-1032, June 1988.

3) United States Nuclear Regulatory Commission, "NRC Information Digest," NUREG-1350, March 1992.

4) H. Mitani, "Magnitude and Frequency of Transient Induced Voltages in Low Voltage Control Circuits of Power Stations and Substations," IEEE Transactions on Power Apparatus and Systems, Vol. PAS-99, No. 5,
September/October 1980.

5)

I. Ikeda, M. Tani, T. Yonezawa, "Analytical Technical of Lightning Surges Induced on Grounding Mesh of PWR Nuclear Power Plant," IEEE Transactions on Energy Conversion, Vol. 5, No. 1, March 1990.

6) R. H. Golde, Lightning, Chemical Pub. Co., New York, 1975.

\section{APPENDIX I - LICENSEE EVENT REPORTS}

Licensee Event Reports (LERs) are identified by seven digit numbers, such as 123-45-67. The first group of three digits, 123 in this example, is from the docket number of the licensee. The docket number for all power plant reactor licenses is 050$00-\mathrm{XXX}$. The second group of two digits, 45 in this example, indicate the year the event was reported, 1945 in our example. The last group of two digits, 67 in this example, indicates that this is the 67th LER for this year from licensee 050-00-123. The LERs have been categorized as follows.

Section 5 - High Frequency Voltage Transients and Low Voltage Effects

LERs 387-83-92, 387-84-28, 387-84-29, 387-86-28, 387-87-7, $387-87-15,387-87-20$, and 387-88-14.

Section 6 - Control Rod Drive Power Supply Overvoltage Protection Actuation

LERs 364-84-4, 364-85-10, 364-91-5, 445-90-28, 454-85-68, $454-$ 87-17, 454-90-11, 456-88-23, 456-89-6, and 456-90-8.

Section 8 - Equipment Damage

LERs 029-91-2, 155-83-13, 272-80-31, 281-91-6, 313-86-4, 387$88-15,412-90-11$, and 456-88-23.

Section 9 - Lightning Dissipation Arrays

LERs 416-88-12, 416-89-10, 416-89-16, 416-91-10, 416-91-12, and 416-92-10.

Chris Rourk, b. Orlando, Florida, April 22, 1962. B.S.E.E. cum laude, University of Florida, 1985; M. Eng., Electric Power Engineering, Rensselaer Polytechnic Institute, 1987. Electrical Engineer, Bechtel Power Corporation, 1985-1986; Advanced Engineer, Westinghouse Electric Corporation, 19871991; Task Manager, Office of Nuclear Regulatory Research, U.S. Nuclear Regulatory Commission, 1991-present. 


\section{DISCUSSION}

Abdul M. Mousa (B.C. Hydro, Vancouver, Canada). I wish to congratulate Mr. Rourk for a very interesting paper. My comments pertain to the use of Lightning Dissipation Arrays. I agree with Mr. Rourk's findings and wish to add the following for the benefit of power utilities who are being bombarded by misleading advertisements from some of the manufacturers of non-conventional lightning rods:

1. Several types of non-conventional lightning rods exist:

a) Devices which are claimed to prevent lightning by use of the point-discharge phenomenon. In those devices, the single tip of the traditional lightning rod is replaced by a large number of sharp points. Similarly, a lightning conductor would be replaced by some form of a barbed wire. This category includes the "Lightning Dissipation Arrays".

b) Lightning rods with radio-active tips. These are claimed to prevent lightning by ionizing the air.

c) Early Streamer Emission (ESE) devices, e.g. the "Pulsar" built in France. These are claimed to have a much larger protective range than that of the traditional Franklin rod because they develop an upward streamer of significant length prior to the occurrence of the "final jump" of the lightning discharge.

2. Mr. Rourk reports a recent case in which Lightning Dissipation Arrays (LDAs) were proven to be incapable of preventing lightning. It should be mentioned here that the U.S. military organizations sponsored an extensive R\&D project on the effectiveness of LDAs during the early 1970s. The results of the subject research were presented during a conference held November 1975, and some of the findings are given hereafter. In the paper by Durrett [7], it was shown by surveillance cameras that lightning did repeatedly strike the "protected" towers at Kennedy Space Centre where LDAs were installed. In the paper by Moore [8], he concluded that the LDA is nothing but a reinvention of the Franklin lightning rod. And in the paper by Bent and Llewellyn [9], it was shown that experience does not support the claims of the manufacturer that LDAs work.

3. The ineffectiveness of radio-active lightning rods is discussed in [10].

4. The claims regarding the effectiveness of ESE devices are based on a lab test similar to that used by the manufacturers of radio-active lightning rods $[11,12]$. As shown in [10], that test does not really prove the point.

5. In summary, lightning cannot be prevented and the benefit from non-conventional lightning rods and conductors, if any, is too small to justify their cost.

\section{REFERENCES}

[7] W.R. Durrett, "Dissipation Arrays at Kennedy Space Centre", pp. 24-52 of Review of Lightning Protection
Technology for Tall Structures, Publication No. ADA075 449, Office of Naval Research, Arlington, Virginia, January 1977.

[8] C.B.Moore, "Study of Behaviour of Sharp and Blunt Lightning Rods in Strong Electric Fields", pp. 96-107 of Review of Lightning Protection Technology for Tall Structures, Publication No. AD-A075 449, Office of Naval Research, Arlington, Virginia, January 1977.

[9] R.B. Bent and S.K. Llewellyn, "An Investigation of the Lightning Elimination and Strike Reduction Properties of Dissipation Arrays", pp. 149-241 of Review of Lightning Protection Technology for Tall Structures, Publication No. AD-A075 449, Office of Naval Research, Arlington, Virginia, January 1977.

[10] A.M. Mousa, Discussion of "An Experimental Study of Ionizing Air Terminal Performance", IEEE Trans. on Power Delivery, Vol. 4, No. 2, pp. 1182-1183, April 1989.

[11] G. Berger and N. Floret, "Collaboration Produces a New Generation of Lightning Rods", pp. 185-190 of Power Technology Intermational, Sterling Publications, London, Britain, 1991.

[12] K.P. Heary et al., "An Experimental Study of Ionizing Air Terminal Performance", IEEE Trans. on Power Delivery, Vol. 4, No. 2, pp. 1175-1181, April 1989.

Manuscript received February 22, 1994.

Chris Rourk (U.S. Nuclear Regulatory Commission, Washington, D.C.) I appreciate Dr. Mousa's comments, and would like to add that the Federal Aviation Administration ("FAA") has determined that lightning dissipation arrays are no more effective than the standard FAA air terminal, which is a conventional lighting rod and ground conductor system for structural protection [13]. It should also be noted that much of the research which has been conducted in this area has not been published in technical journals. The studies conducted for the Office of Naval Research are only available through the National Technical Information Service, and the FAA study is only available through the FAA by a Freedom of Information Act request, per a decision by the FAA's General Counsel.

\section{REFERENCES}

[13] "I989 Lightning Protection Multipoint Discharge Systems Tests: Orlando, Sarasota, and Tampa, Florida," FAATC T16 Power Systems Program, ACN-210 Final Report, 12/31/90.

Manuscript received April 11, 1994. 